\title{
THE WETTABILITY OF COKE BY PITCHES WITH DIFFERENT QUINOLINE- INSOLUBLE CONTENTS
}

\author{
Ying Lu ${ }^{1}$, Duygu Kocaefe ${ }^{1 *}$, Yasar Kocaefe ${ }^{1}$, Xian-Ai Huang ${ }^{1}$, Dipankar Bhattacharyay ${ }^{1}$ \\ ${ }^{1}$ UQAC/AAI Research Chair on Carbon and REGAL Aluminum Research Center \\ University of Quebec at Chicoutimi 555 Boulevard de l'Université, Chicoutimi, QC, Canada \\ G7H 2B1 \\ Ying Lu¹, (ying.lu1@uqac.ca) \\ Duygu Kocaefe ${ }^{1 *}$, (Duygu_Kocaefe@uqac.ca), \\ Yasar Kocaefe ${ }^{1}$, (Yasar_Kocaefe@uqac.ca) \\ Xian-Ai Huang ${ }^{1}$, (xianai.huang1@uqac.ca) \\ Dipankar Bhattacharyay, (Dipankar_Bhattacharyay@uqac.ca) \\ Corresponding author: Duygu_Kocaefe@uqac.ca
}

Tel: 418-545-5011 ext 5215

\begin{abstract}
The properties of pitch as the binder material for carbon anode manufacturing strongly affect the anode properties. Pitches show significant differences in their chemical composition depending on their origin. In this study, five coal tar pitches with different quinoline-insoluble (QI) contents were studied to understand the wettability of these pitches on one calcined petroleum coke using the sessile-drop test. The chemical properties of the coke and pitch were studied using XPS and FT-IR to investigate their wetting mechanism and their interactions. The structures of different pitches and the pitch-coke interface were characterized by optical microscopy and SEM, respectively. The results showed that not only the chemical but also the physical properties of the pitches contribute to the wettability of coke. The wettability increases with increasing heteroatom content in the pitch. The viscosity of pitch is a key parameter controlling the wetting behavior of pitch. The QI content, the solid particle size and distribution in the pitches play a significant role in the wettability of coke by pitch.
\end{abstract}




\section{Keywords}

Wetting behavior, coke, pitch, QI contents, solid particles, particle size distribution.

\section{Introduction}

Prebaked carbon anodes are used in the electrolytic alumina reduction process to produce aluminum in industry. Dry aggregates consisting of approximately 65\% petroleum coke and 20\% recycled anodes and butts are mixed with 15\% coal tar pitch [1]. As the binder in carbon anodes, coal tar pitch has an important influence on anode quality. Good binding between dry aggregates and pitch results in dense anodes, thus greatly affecting the final anode properties [1] .

Wettability of coke by pitch is one of the important parameters which determine the quality of binding between coke and pitch [2]. The contact angle is a measure of the ability of a liquid to spread on the solid surface and penetrate through it if the solid is porous [2-7]. It is reported in the literature that the sessile-drop technique, during which the change in contact angle with time is monitored under an inert gas atmosphere, can be used successfully for wettability studies [27].

Many authors found that the wetting behavior between pitch and substrate depends on the properties of both the pitch and substrate [4-8]. Rocha et al. [4, 5] studied the effect of the chemical composition and structural order of the substrates (petroleum coke as the substrate, with several substrates prepared by thermal treatment from petroleum pitch) on the pitch/substrate wetting behavior. Rocha et al. [4] also studied pitch/coke wetting behavior and showed that pitch wetting behavior is related to both surface tension and viscosity of pitch. Sarkar et al. [7] investigated the dynamic contact angles and the interaction of different cokes by pitch, and reported that the wettability behavior of cokes by pitches is dependent on the presence of the surface functional groups in the coke and pitch that could form chemical bonds. Huang et al. [9] studied the wettability of bio-coke by pitch and found that the surfaces of bio-cokes have a different chemical nature from that of the petroleum coke, resulting in a better wettability of biocoke by pitch compared to the petroleum coke.

However, quinoline-insoluble (QI) contents have also been used to evaluate the properties of binder pitches used for anodes. Jones et al. [10] reported that a limited quantity of primary QI in binder pitch increases the bond strength and mechanical strength, and protects the underlying filler from both air-burn and $\mathrm{CO}_{2}$ oxidation. A large quantity of primary QI and carbon black can 
reduce the binding capacity of pitch. The absence of primary QI causes a high anisotropy of the binder-coke bridges [11] and generates higher flow conditions, resulting in an inferior strength [12]. Sakai et al. found that a limited amount of primary QI is necessary for optimized properties of the binder pitch [12]. Wombles et al. [13] reported that a substantial proportion (3-10\%) of mesophase $(>4 \mu \mathrm{m})$ blocks the micropores of coke and prevents the infiltration of binder pitch and fine particles into the pores of the filler coke. This is detrimental to anode density and adversely affects the mechanical strength and reactivity [14].

For the effect of QI content on anode properties, there are conflicting results in the literature. Table 1 summarizes the findings of different researchers.

Table 1: Studies on the effect of QI content on anode properties

\begin{tabular}{|c|c|c|}
\hline QI content & Effect of QI content on anode properties & Reference \\
\hline $6-8.5 \%$ & $\begin{array}{l}\text { Provides optimum wetting behavior, helps } \\
\text { producing high performance baked anode }\end{array}$ & {$[12]$} \\
\hline $9-22 \%$ & $\begin{array}{l}\text { High QI content does not deteriorate the } \\
\text { wettability of pitch on coke }\end{array}$ & [15] \\
\hline$<13 \%$ & Helps improve anode properties & {$[16]$} \\
\hline $1-5 \%$ and $5-20 \%$ & $\begin{array}{l}\text { Change in QI levels does not affect anode } \\
\text { properties }\end{array}$ & {$[12,17-19]$} \\
\hline $1-2 \%$ & $\begin{array}{l}\text { Minimum QI level required for acceptable baked } \\
\text { anode properties }\end{array}$ & {$[20]$} \\
\hline $\begin{array}{l}\text { Medium to high QI } \\
\text { content }\end{array}$ & Correlates with superior anode quality & {$[18,21]$} \\
\hline $\begin{array}{l}\text { Low primary QI } \\
\text { content }\end{array}$ & $\begin{array}{l}\text { Requires process modifications to improve anode } \\
\text { properties }\end{array}$ & {$[18,21]$} \\
\hline
\end{tabular}

As can be seen from this table, studies do not agree on the optimum primary QI level of pitch required to have a good quality anode. This is probably because the anode properties are affected by not only the QI level but also the QI particle size and the structure of coke used. However, there does not seem to be any published study on the effect of the sizes of the solid particles or their size distribution as well as different QI contents on the wettability of coke by pitch. The objective of this study is to investigate the wetting of coke by pitches with different QI contents using the sessile-drop wetting system. The chemical properties of coke and pitch were studied using FT-IR and XPS. This study also involves the optical microscopy characterization of the QI 
particle size and their distribution in pitch. Furthermore, the pitch-coke interfaces were investigated using SEM.

\section{Methodology}

\subsection{Materials used}

Five coal-tar pitches with different QI contents were used as binders in this study. Table 2 summarizes the main properties of these pitches. A calcined petroleum coke was chosen as the substrate and was obtained by sieving the as-received coarse sample to a $100-125-\mu \mathrm{m}$ size [22]. The wettability of these pitches on coke was investigated for comparison.

Table 2: Properties of different coal tar pitches

\begin{tabular}{|c|c|c|c|c|c|}
\hline Pitch type & S.P.* & Q.I.* & ß-resin* & CV $^{*}$ & $\mu^{*}$ \\
\hline Pitch-1 & 118.4 & 3.4 & 22.5 & 58.9 & 1200 \\
\hline Pitch-2 & 119.6 & 6.9 & 22.2 & 59.1 & 1390 \\
\hline Pitch-3 & 118.0 & 10.8 & 22.2 & 61.2 & 1445 \\
\hline Pitch-4 & 121.5 & 7.5 & 22.1 & 59.9 & 2070 \\
\hline Pitch-5 & 119.4 & 5.1 & 22.9 & 59.6 & 1700 \\
\hline
\end{tabular}

*S.P.: softening point $\left({ }^{\circ} \mathrm{C}\right.$ ), Q.I.: quinoline-insolubles (wt \%), ß-resin: beta resin (wt \%), $\mathrm{CV}$ : coking value (wt \%), $\mu$ : viscosity at $170{ }^{\circ} \mathrm{C}$ (mPa.s).

\subsection{Coke porosity analysis}

The porosity distribution in the coke sample $(100-125 \mu \mathrm{m})$ was measured by BET equipment (Gemini VII Surface Area and Porosity, Micrometrics) using nitrogen gas. Adsorption and desorption of nitrogen at liquid nitrogen temperature were measured for relative pressure in the range of 0 to 1 . Barrett-Joyner-Halenda $(\mathrm{BJH})$ analysis method was used to measure the porosity distribution based on the adsorption-desorption data.

\subsection{Sessile drop wetting system}

In this study, the wetting behavior of the pitch was determined using a sessile drop system at $170{ }^{\circ} \mathrm{C}$, which is the common temperature of mixing used in industry. The sessile drop system consists of a tube furnace purged with gas (nitrogen), a pitch injection system, a graphite sample crucible, a digital video camera, and a vacuum pump (Figure 1). The coke sample is placed into 
the graphite sample crucible and is compacted to achieve a smooth coke bed surface. The injection chamber holds the solid pitch sample. This chamber has a small hole in its body and is placed just above the coke substrate by arranging the position of the injection chamber hole during the experiment. The experiments were conducted in vacuum under a nitrogen atmosphere. To decrease the $\mathrm{O}_{2}$ and humidity content of $\mathrm{N}_{2}$, the gas is passed through $\mathrm{O}_{2}$ and humidity traps before entering the system. There are two entry lines for nitrogen. The main line is directly connected to the furnace tube for maintaining the inert atmosphere inside the tube. The other line that connects the injection chamber to the inert gas supply carries the nitrogen gas required to slightly pressurize this chamber to force the molten pitch droplet out onto the coke substrate. A video of the drop is captured, and the images are saved on a computer. To measure the contact angle, FTA 32 software is used. Each experiment was repeated twice, and the contact angle was taken as the average of these two results. After the experiments, the pitch-coke drops were cut vertically and studied with SEM.

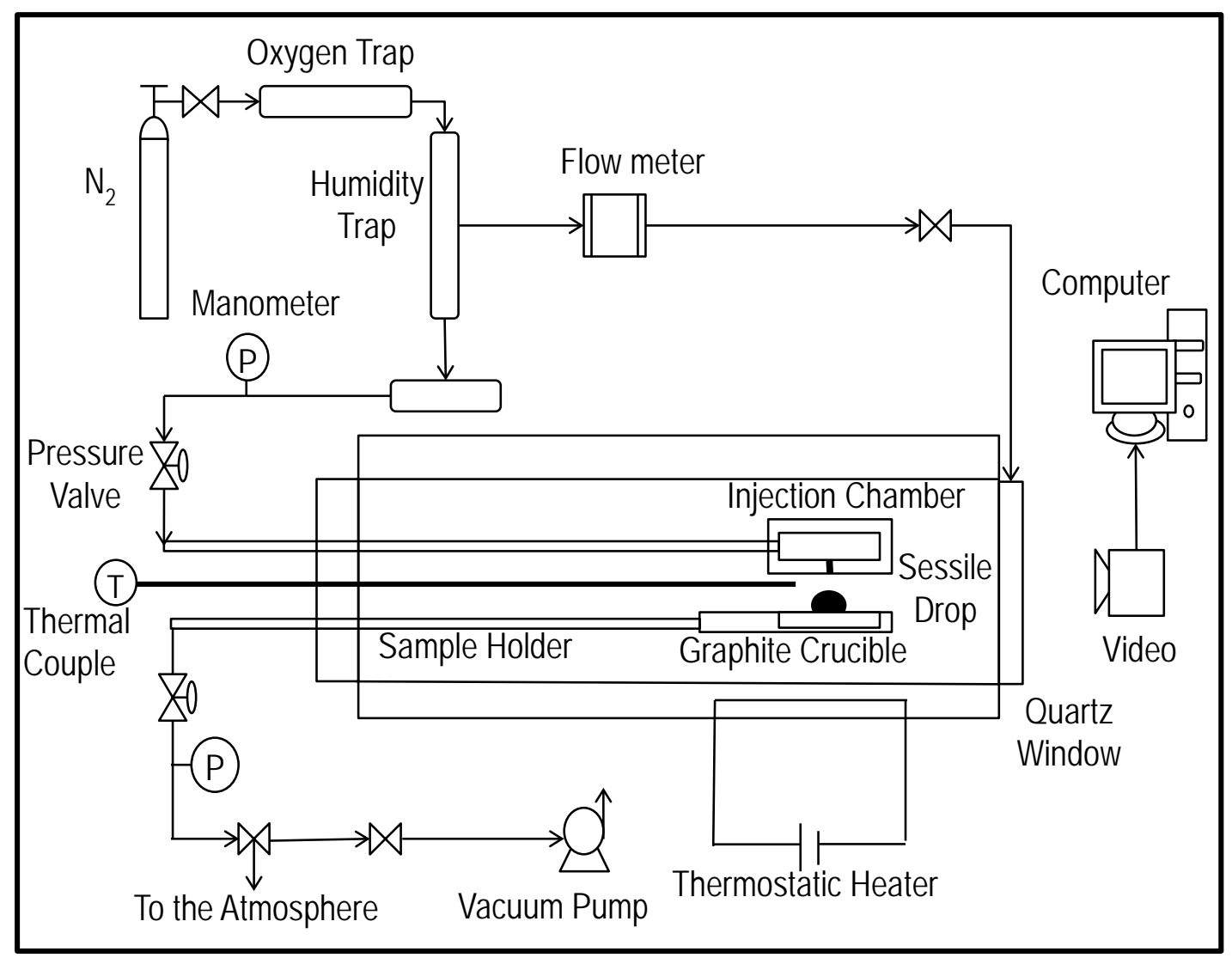

Figure 1: Schematic diagram of sessile drop experimental set-up at UQAC. 


\subsection{FT-IR spectroscopy analysis}

FT-IR is a powerful tool used to detect different functional groups based on bond energies. FT-IR can also detect different hybridizations of carbon present in $\mathrm{CH}$ bonds and can identify aromatic and aliphatic hydrocarbons, which are difficult to analyze with XPS. The chemical structures of calcined petroleum coke and those of the five coal tar pitches were qualitatively examined by FT-IR spectroscopy at room temperature. The main objective was to identify the compliment functionality between pitch and coke, as well as to compare the chemical functionality of different pitches. IR spectra were collected in the wave number range of 500$4000 \mathrm{~cm}^{-1}$, and all of the spectra were recorded at a $4-\mathrm{cm}^{-1}$ resolution. For each run, 64 scans were performed prior to the Fourier transformation. All of the spectra were collected using a $\mathrm{KBr}$ technique (the ratio of sample to $\mathrm{KBr}$ was 1:100), the spectrum version 5.0.1 software was used, and the result was taken as the average of two experiments. The IR spectra for each experimental set were transformed into absorbance spectra.

2.5 XPS analysis

The surface quantitative chemical analysis of coke as well as coal tar pitches can be obtained by X-ray photoelectron spectroscopy (XPS). XPS analysis provides information about the distribution and content of different atoms and the nature of the corresponding bonds on the surface based on their electronic binding energy. In this study, the samples were ground to -125 $\mu \mathrm{m}$ and were analyzed using an AXIS Ultra XPS spectrometer (Kratos Analytica) with a monochromate $\mathrm{Al} \mathrm{K}[\alpha](\mathrm{h} v=1486.6 \mathrm{eV})$ source at a power of $210 \mathrm{~W}$ at the Alberta Centre for Surface Engineering and Science (ACSES), University of Alberta. The XP-spectra fitting was performed using CasaXPS software. The detailed analysis procedure and parameters used were described in a previous publication [7]. The analyzed surface depth of the sample was 2-5 nm.

2.6 Optical microscopy analysis

Optical microscopy allows the visualization of the solid particle content of the polished solidified pitches. The epoxy liquid resin was chosen for the preparation of polished blocks for different pitches to be observed in this study. Polishing was performed using Struers Polisher to create a scratch-free surface. The optical microscopy image analysis was performed using Nikon Eclipse ME600P optical microscope and was analyzed by Clemex Vision 4.0 image analysis software. 


\subsection{SEM analysis}

The solidified pitch drops on calcined petroleum coke after the sessile-drop tests were sectioned vertically and polished for image analysis of the pitch-coke interface using SEM. This allows the visualization of the pitch structures and the penetration into the coke bed as well as the interface between the pitch and the coke particles. The SEM analysis was performed using a JEOL-JSM-6480LV with secondary electron scattering and with a voltage of $20 \mathrm{kV}$ and a WD of 21-22 mm.

\section{Results and discussion}

3.1 Porosity distribution of coke

The BJH adsorption and BJH desorption average pore widths were found to be 0.267 and $0.193 \mu \mathrm{m}$ respectively. Figure 2 shows the porosity distribution in a coke sample (100-125 $\mu \mathrm{m})$. The result shows that the width of the most of the pores is around $0.2 \mu \mathrm{m}(2000 \AA)$ with a maximum around $0.3 \mu \mathrm{m}(3000 \AA)$.

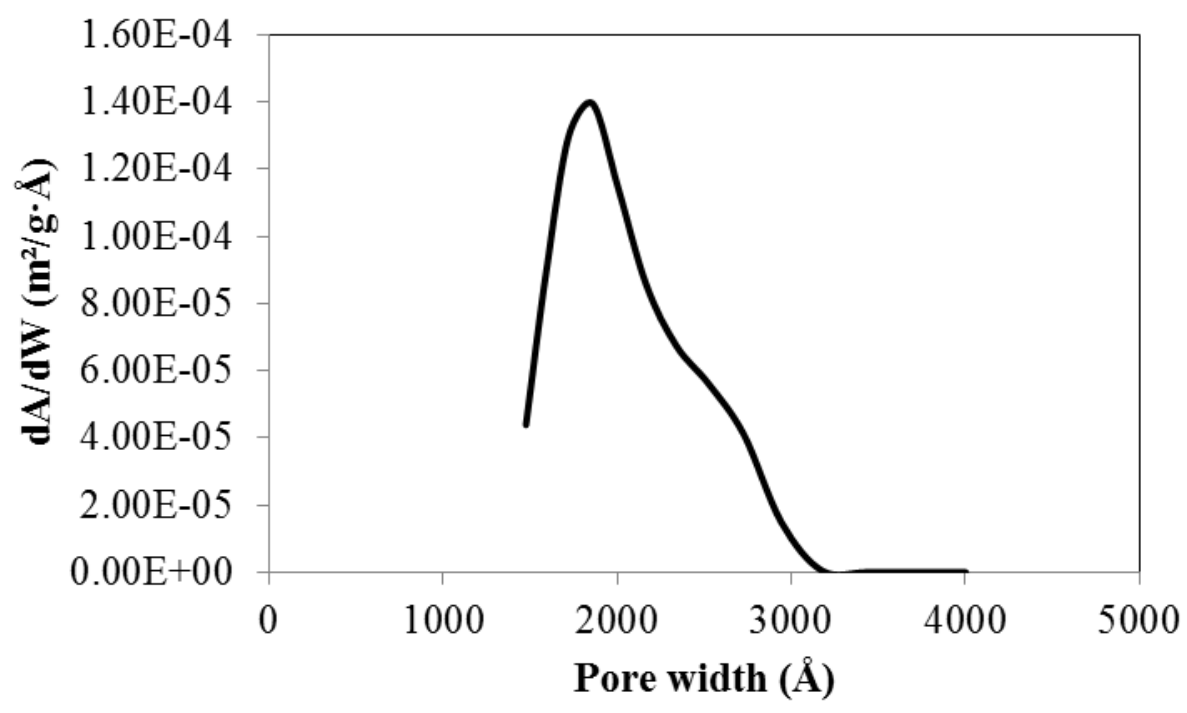

Figure 2 Porosity distribution of coke particles (100-125 $\mu \mathrm{m})$

The inter-particular space was calculated based on Figure 3. Figure 3 shows the orientation of $112.5 \mu \mathrm{m}$ particles (average size of particles used) for high packing density. As the coke particles are packed well before doing the wettability experiment the packing shown in Figure 3 was chosen. Figure 3 shows that the maximum size of the particle that can enter between the 112.5 $\mu \mathrm{m}$ particles is $18 \mu \mathrm{m}$. 


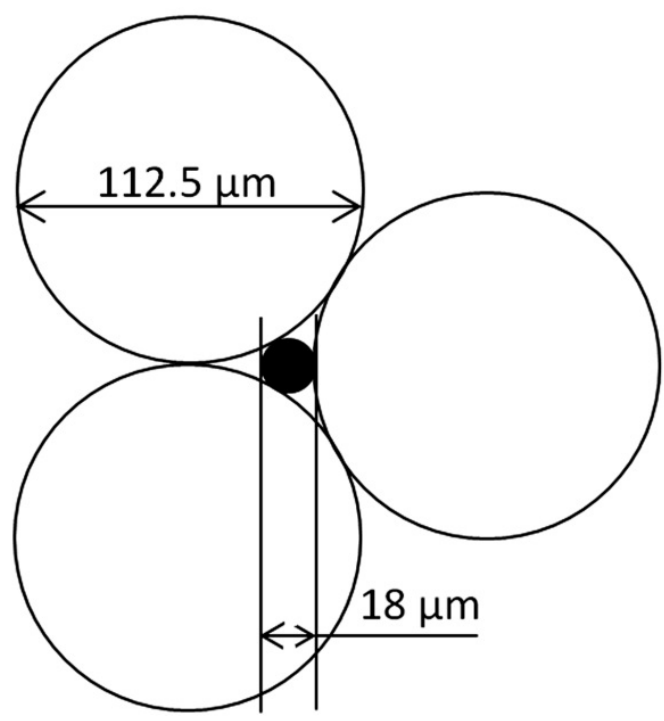

Figure 3. Size of particle that can enter in inter-particular space

This analysis was carried out to estimate that the maximum size of solid particles of pitch that can fit into the coke pores as well as pass between the particles. This will be explained in more detail in Sections 3.4 to 3.6.

\subsection{Wettability of coke by different pitches}

The wettability of coke by pitch, which is used as the binder in anodes, affects the properties of the anodes. Pitches show significant differences in their chemical composition and physical behavior depending on their origins. Five different coal tar pitches with similar softening points (Pitch 1, Pitch 2, Pitch 3, Pitch 4 and Pitch 5) were studied to understand the interaction between different pitches and one calcined petroleum coke using the sessile-drop wetting test.

Figure 4 shows the wetting test results for five different pure pitches with different properties. The contact angle decreases with increasing time, and a smaller contact angle indicates a better wettability. It can be seen that the initial contact angles differed by approximately $10^{\circ}$ between different pitches, while the duration for complete penetration/spreading into the coke bed are significantly different. Pitch-1 required the least amount of time (most penetrating), and Pitch-5 required the most time (least penetrating) for complete penetration/spreading. However, it can be observed that the contact angle values of these pitches at a specific time (60 s) followed the trend of Pitch-4 $>$ Pitch-5 $>$ Pitch-3 $>$ Pitch-2 $>$ Pitch-1. The time was chosen as $60 \mathrm{~s}$ because the typical kneading time for coke and pitch in anode plants is usually around $60 \mathrm{~s}$. The kneading 
time indicates the mixing time of coke and pitch. Thus, according to the results at $60 \mathrm{~s}$, Pitch-5 and Pitch-4 show similar contact angles (contact angle for Pitch-4 is slightly higher), and the wettability of coke by pitch in descending order is as follows: Pitch-1 > Pitch-2 > Pitch-3 > Pitch-5 >Pitch-4. It can be seen that, before $80 \mathrm{~s}$, the wettability of pitch by coke is in the following decreasing order: Pitch- $1>$ Pitch- $2>$ Pitch-3 $>$ Pitch-5 $>$ Pitch-4. After 80 s, the wettability of coke by Pitch-5 was less than that by Pitch-4.

It was reported in the literature that the interaction between coke and pitch depends on the properties of both the pitch (i.e., chemical composition, surface tension, viscosity, QI, mesophase content, etc.) and the coke (e.g. particle size, structure, texture, chemical functional groups on the surface, porosity, etc.) $[5,6,8]$. In this study, the same coke was used for all the experiments. Thus, the effects of physical (viscosity, QI amount, size of solid particles) and chemical properties (heteroatoms, functional groups) of different pitches on their wettability were studied. The effect of chemical properties of coke and pitch were studied using FT-IR and XPS. The pitches with different QI contents were characterized with optical microscopy. Furthermore, the pitch-coke interfaces were investigated using SEM.

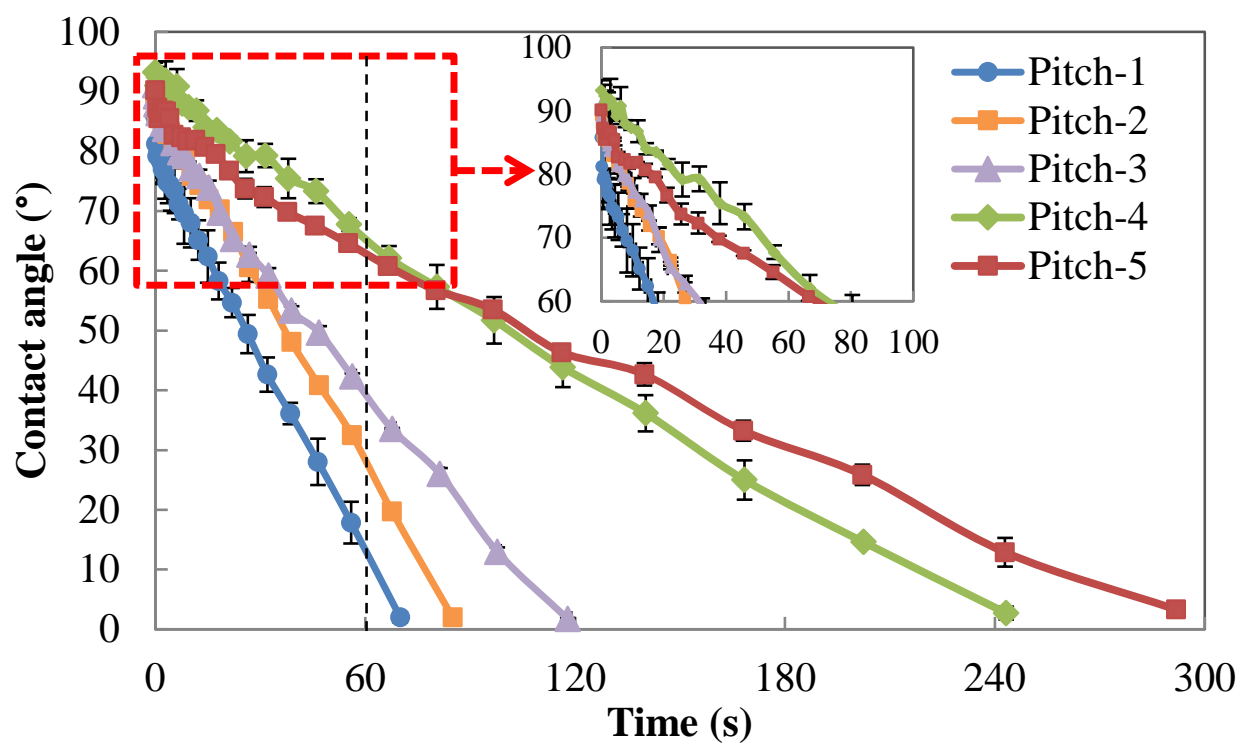

Figure 4: Contact angles of different pitches. 


\subsection{FT-IR analysis}

The qualitative analysis of the chemical groups in pitch and coke were carried out using FTIR. From the FT-IR spectra shown in Figure 4, it can be observed that there are similar chemical functionalities in the five different coal tar pitches. The band at $750 \mathrm{~cm}^{-1}$ is due to the orthosubstituted aromatic ring vibrations $[6,23]$. The region of 700-900 $\mathrm{cm}^{-1}$ includes various bonds related to the aromatic out-of-plane vibration and $\mathrm{C}-\mathrm{H}$ bending with different degrees of substitution [6, 23]. The regions between $2800-2980 \mathrm{~cm}^{-1}$ and $1480-1370 \mathrm{~cm}^{-1}$ are for aliphatic hydrogen (stretching vibrations) due to the $-\mathrm{CH}_{2}$ and $-\mathrm{CH}_{3}$ structures for the coal tar pitches [6]. The band at 3000-3100 $\mathrm{cm}^{-1}$ relates to aromatic hydrogen (stretching vibrations) [23]. The band at $1600 \mathrm{~cm}^{-1}$ is due to aromatic $\mathrm{C}=\mathrm{C}$ stretching vibrations. The weak band at about $1720 \mathrm{~cm}^{-1}$ is for $\mathrm{C}=\mathrm{O}$. The band at $1000-1200 \mathrm{~cm}^{-1}$ relates to $\mathrm{C}-\mathrm{O}$ group, which could be assigned to alcohol/phenols/ether. Presence of both $\mathrm{C}=\mathrm{O}$ and $\mathrm{C}-\mathrm{O}$ can indicate the presence of carboxylic acid or ester [23]. A wide peak around $3428 \mathrm{~cm}^{-1}$ is for free moisture. Multiple peaks in the region of $1200-1300 \mathrm{~cm}^{-1}$ are due to C-O /C-N vibrations [6]. All the pitches contain the above chemical functional groups. Therefore, it is difficult to identify the differences in chemical groups of different pitches.

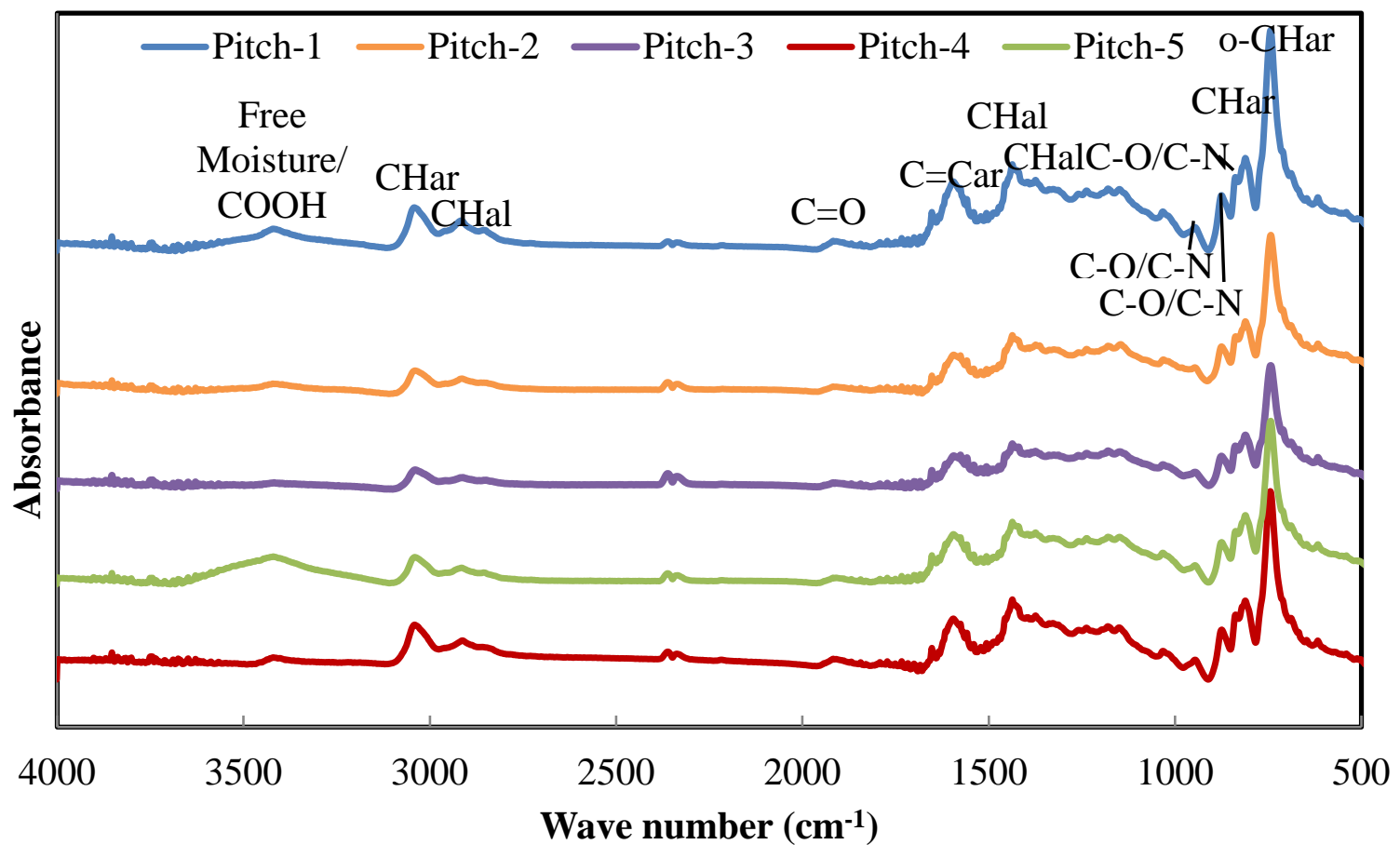

Figure 4: FT-IR spectra of five different coal tar pitches 
Figure 5 shows the FT-IR spectra of the calcined petroleum coke used in the wetting test. The band at region of 3400-3600 $\mathrm{cm}^{-1}$ is related to free moisture/phenol/carboxylic acid [7]. The band at $3452 \mathrm{~cm}^{-1}$ is due to $\mathrm{N}-\mathrm{H}$ groups in carbazole/secondary amine/OH stretching vibrations. The band at $3000-3100 \mathrm{~cm}^{-1}$ is due to aromatic hydrogen stretching vibrations. The region between 3000 and $2700 \mathrm{~cm}^{-1}$ are due to C-H stretching vibrations of alkyl substituents and methylene groups in hydro aromatic compounds [7]. A peak near $750 \mathrm{~cm}^{-1}$ shows the ortho-substitution of the aromatic ring. Amines (C-N) or ethers (C-O-C) are found in the region around $1100 \mathrm{~cm}^{-1}$. Band corresponding to aromatic $\mathrm{C}=\mathrm{C}$ bond can be seen near $1500 \mathrm{~cm}^{-1}$. Carbonyl $(\mathrm{C}=\mathrm{O})$ group can be found in the region around $1800 \mathrm{~cm}^{-1}$. Two peaks near $1200 \mathrm{~cm}^{-1}$ and $1350 \mathrm{~cm}^{-1}$ are due to corresponding C-O stretching vibrations in ester/ether/acid and C-O-C vibrations in esters/carboxylic acid/ether [7].

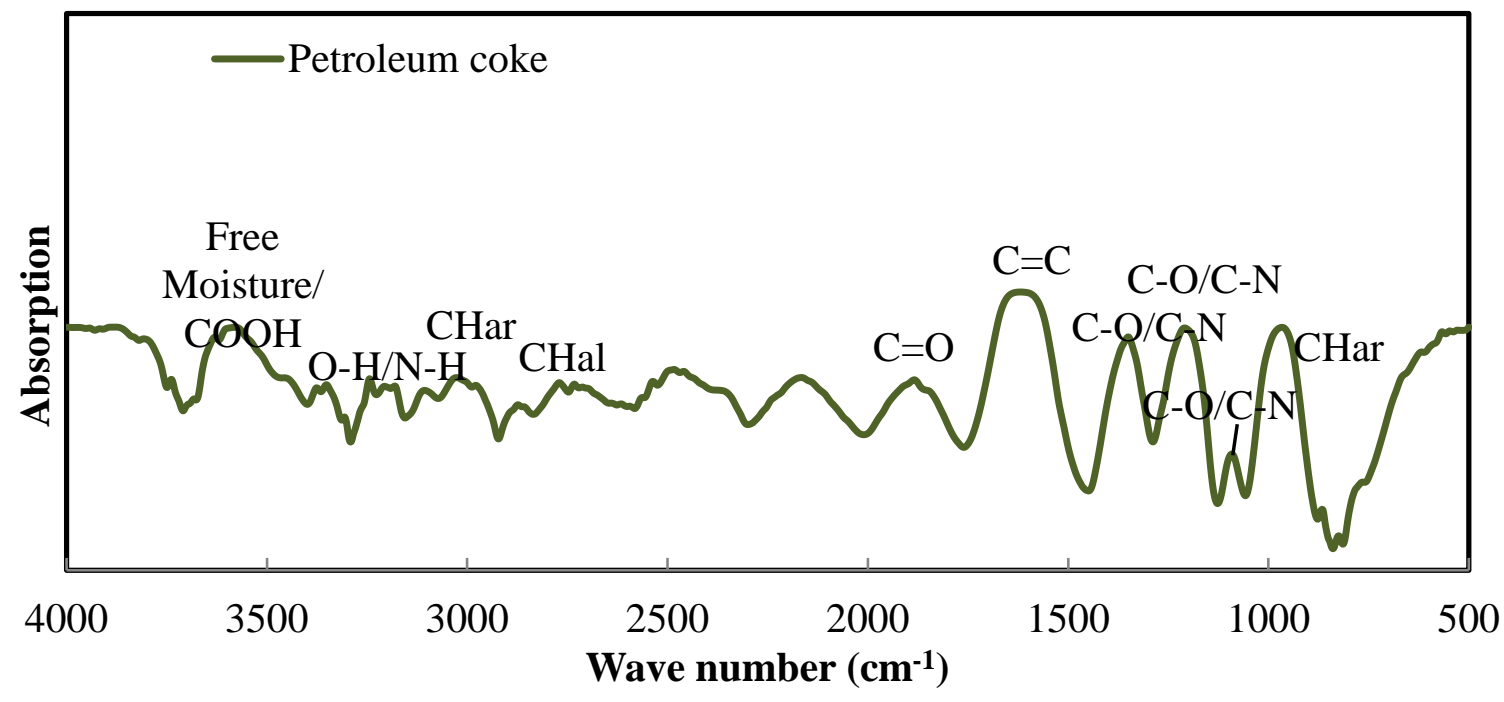

Figure 5: FT-IR spectra of calcined petroleum coke

There are usually three types of chemical interactions between coke and pitch samples [9]. The first interaction is a hydrogen bond between a hydrogen atom attached to a highly electronegative atom $(\mathrm{O}, \mathrm{N})$ and another electronegative atom $(\mathrm{O}, \mathrm{N})$. Thus, the hydrogen of the $\mathrm{O}-\mathrm{H}$ group can form a hydrogen bond with functional groups containing oxygen (hydroxyl, ether, and carboxylic groups) or nitrogen atoms (amine). The second type is the acid-base interaction. In this case, acidic functional groups (carboxylic, phenolic) can interact with basic functional groups (amine). The third type consists of electrostatic interactions. In this case, the negatively charged pi electron cloud of aromatic rings can form electrostatic bonds with 
positively charged centers (e.g., a quaternary ammonium ion). Coal tar pitch and petroleum coke contain $\mathrm{O}-\mathrm{H}, \mathrm{C}-\mathrm{N}$, and $\mathrm{COOH}$ groups, as well as aromatic rings, indicating that the petroleum coke and the coal tar pitch possess complimentary functional groups. Thus, it might be possible that the functional groups on the coke surfaces may interact with the complementary functional groups present in pitches.

\subsection{XPS analysis}

Using XPS, the quantity of functional groups close to the surface can be found. Figure 6 (a) shows an example of the survey spectra obtained by an XPS scan for Pitch-2. The most prominent peak at $284.5 \mathrm{eV}$ was designated as $\mathrm{C} 1 \mathrm{~s}$, and other notable peaks were the O1s peak at $533 \mathrm{eV}$ and N1s peak at $400 \mathrm{eV}$. The relative positions of these peaks can be used to determine the chemical nature of these atoms. High-resolution scans and a peak fit for the C1s region are shown in Figure 6 (b), providing quantitative information about the different functional groups based on the deconvolution of C1s binding energies. Deconvolution of Figure 6 (b) reveals three peaks located at $284.3 \mathrm{eV}, 285.1 \mathrm{eV}$ and $286 \mathrm{eV}$ which form the C1s peak. The dominant peak at $284.3 \mathrm{eV}$ is associated with the $\mathrm{C}=\mathrm{C}$ bond of aromatic structures. The $285.1 \mathrm{eV}$ peak corresponds to the C-C bond of aliphatic structures. An approximation was made such that the binding energy corresponding to the range of $285.5 \mathrm{eV}$ to $289 \mathrm{eV}$ with a peak at $286 \mathrm{eV}$ corresponds to a number of functional groups, such as $\mathrm{C}-\mathrm{N} / \mathrm{C}-\mathrm{O} / \mathrm{C}-\mathrm{S} / \mathrm{C}=\mathrm{O} / \mathrm{C}-\mathrm{SO}_{2} / \mathrm{COOH}$.
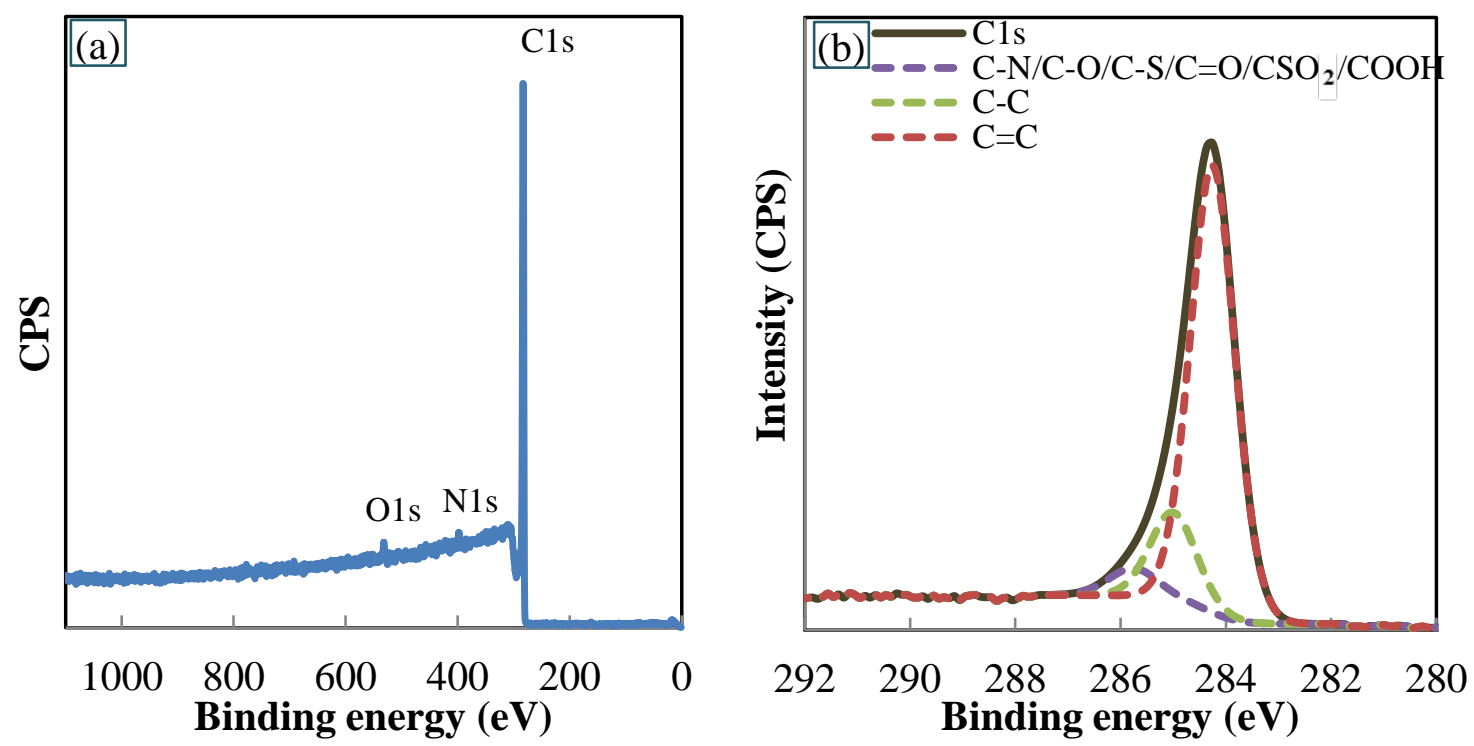

Figure 6: XPS spectra of Pitch-2 (a) survey spectra and (b) de-convoluted C1s spectra. 
Table 3 summarizes the atomic percentages of different components of the pitches and calcined coke for the survey spectra and the de-convoluted C1s spectrum. It can be seen from this table that coke contains high amount of heteroatoms. Different pitches contain different amount of $\mathrm{C}=\mathrm{C}$, $\mathrm{C}-\mathrm{C}$, functional groups and heteroatoms. A good linear correlation was observed between the contents of $\mathrm{CN} / \mathrm{CO} / \mathrm{CS} / \mathrm{C}=\mathrm{O} / \mathrm{CSO}_{2} / \mathrm{COOH}$ groups and heteroatoms $(\mathrm{O}, \mathrm{N}$ and $\mathrm{S})$ contents for different pitches (Figure 7 a). The percentages of $\mathrm{CN} / \mathrm{CO} / \mathrm{CS} / \mathrm{C}=\mathrm{O} / \mathrm{CSO}_{2} / \mathrm{COOH}$ groups increase with increasing heteroatoms $(\mathrm{O}, \mathrm{N}$ and $\mathrm{S})$ contents. It is reported in the literature that increasing heteroatom content increases the wettability of coke by pitch [9]. The wettability results presented in Section 3.2 showed that the order of wettability of the pitches used in this project in decreasing order is Pitch-1 $>$ Pitch-2 $>$ Pitch-3 $>$ Pitch-5 $>$ Pitch-4 (Figure 7 b). The results are in agreement with the literature for all the pitches with the exception of Pitch-5 (shown in red in Figure $7 \mathrm{~b}$ ) showing that there might be other factors influencing the wettability. Pitch-5 has high heteroatom content. Still it showed wettability close to that of Pitch-4 which has the lowest heteroatom content. This will be explained in more detail in the following sections.

Table 3: Atomic percentages of different components of the raw materials

\begin{tabular}{|c|c|c|c|c|c|c|c|c|}
\hline \multirow{2}{*}{ Material } & \multirow{2}{*}{ C (\%) } & \multicolumn{3}{|c|}{ Carbon (C1s) functional groups (\%) } & \multirow{2}{*}{$\begin{array}{l}\mathrm{O} \\
(\%)\end{array}$} & \multirow{2}{*}{$\begin{array}{l}\mathrm{N} \\
(\%)\end{array}$} & \multirow{2}{*}{$\begin{array}{c}\mathrm{S} \\
(\%)\end{array}$} & \multirow{2}{*}{$\begin{array}{c}\text { Total } \\
\text { heteroatoms } \\
\mathrm{O}+\mathrm{N}+\mathrm{S}(\%)\end{array}$} \\
\hline & & $\mathrm{C}=\mathrm{C}$ & $\mathrm{C}-\mathrm{C}$ & $\begin{array}{c}\mathrm{CN} / \mathrm{CO} / \mathrm{CS} \\
/ \mathrm{C}=\mathrm{O} / \mathrm{CSO}_{2} / \mathrm{COOH}\end{array}$ & & & & \\
\hline Pitch-1 & 96.62 & 81.42 & 13.00 & 5.58 & 1.89 & 1.21 & 0.29 & 3.39 \\
\hline Pitch-2 & 96.93 & 78.66 & 15.96 & 5.38 & 1.74 & 1.07 & 0.25 & 3.06 \\
\hline Pitch-3 & 97.88 & 79.41 & 16.74 & 3.85 & 1.15 & 0.7 & 0.26 & 2.11 \\
\hline Pitch-4 & 98.08 & 75.01 & 21.03 & 3.69 & 1.21 & 0.51 & 0.2 & 1.92 \\
\hline Pitch-5 & 97.61 & 81.29 & 14.42 & 4.29 & 1.18 & 0.94 & 0.27 & 2.39 \\
\hline Coke & 95.89 & 80.54 & 12.21 & 7.25 & 2.53 & 0.60 & 0.98 & 4.11 \\
\hline
\end{tabular}




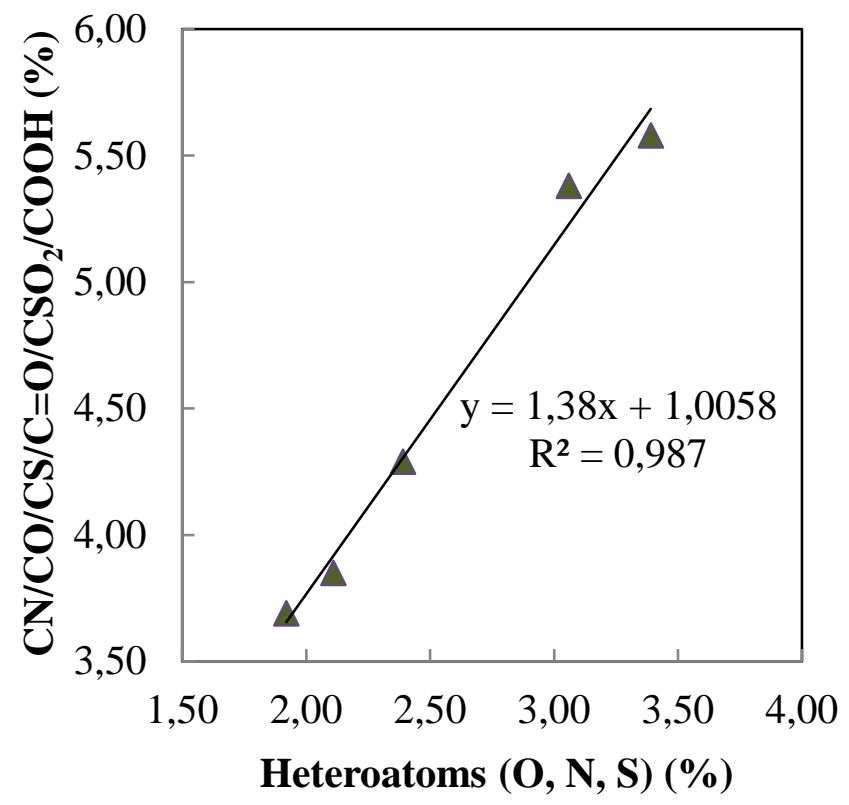

(a)

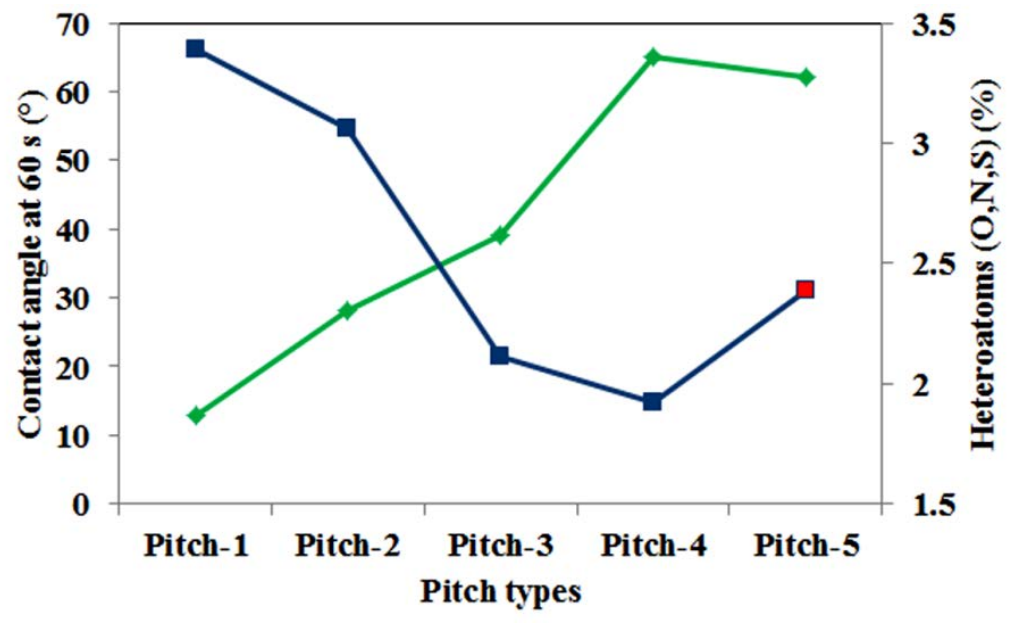

(b)

Figure 7: (a) Correlation between the contents of $\mathrm{CN} / \mathrm{CO} / \mathrm{CS} / \mathrm{C}=\mathrm{O} / \mathrm{CSO}_{2} / \mathrm{COOH}$ and heteroatom (O, N and S) contents in different pitches, (b) relationship between contact angle at $60 \mathrm{~s}$ and heteroatom $(\mathrm{O}, \mathrm{N}$ and $\mathrm{S})$ contents.

3.5 Optical microscopy analysis 
Results showed that there is a difference in the wettability of the same coke with different pitches. Table 2 compares the properties of different pitches. Even though the S.P., Beta resin, and coking value of the pitches are similar, their QI contents and viscosities are different. The pitch structure was investigated using an optical microscope in order to see the differences in QI particle size of the pitches and the effect of this on wettability. As reported in the literature, the QI can be divided into two categories: primary QI and secondary QI [1, 24, 25]. The primary QI particles that are formed in the coke oven can be beneficial for anode quality [1]. The primary QI can be grouped into normal primary QI and carbon black/carry-over. The size of normal primary QI particles is approximately $1 \mu \mathrm{m}$. The size of carbon black particles $(5-500 \mu \mathrm{m})$ is larger because of the agglomeration of small particles. Secondary QI particles are formed during the thermal treatment of pitch at a temperature greater than $400{ }^{\circ} \mathrm{C}$. They are anisotropic and can be classified as mesophase ( $>4 \mu \mathrm{m})$ and mesogens $(2-4 \mu \mathrm{m})$. Optical microscopy is an important tool used to visualize the particles in the pitches. Figure 8 (a-e) shows the images of five pitches, as received. It is possible to observe the solid particles in all of the pitches. It can be seen that the pitch contains many particles; some of them remain isolated and some are agglomerated. 

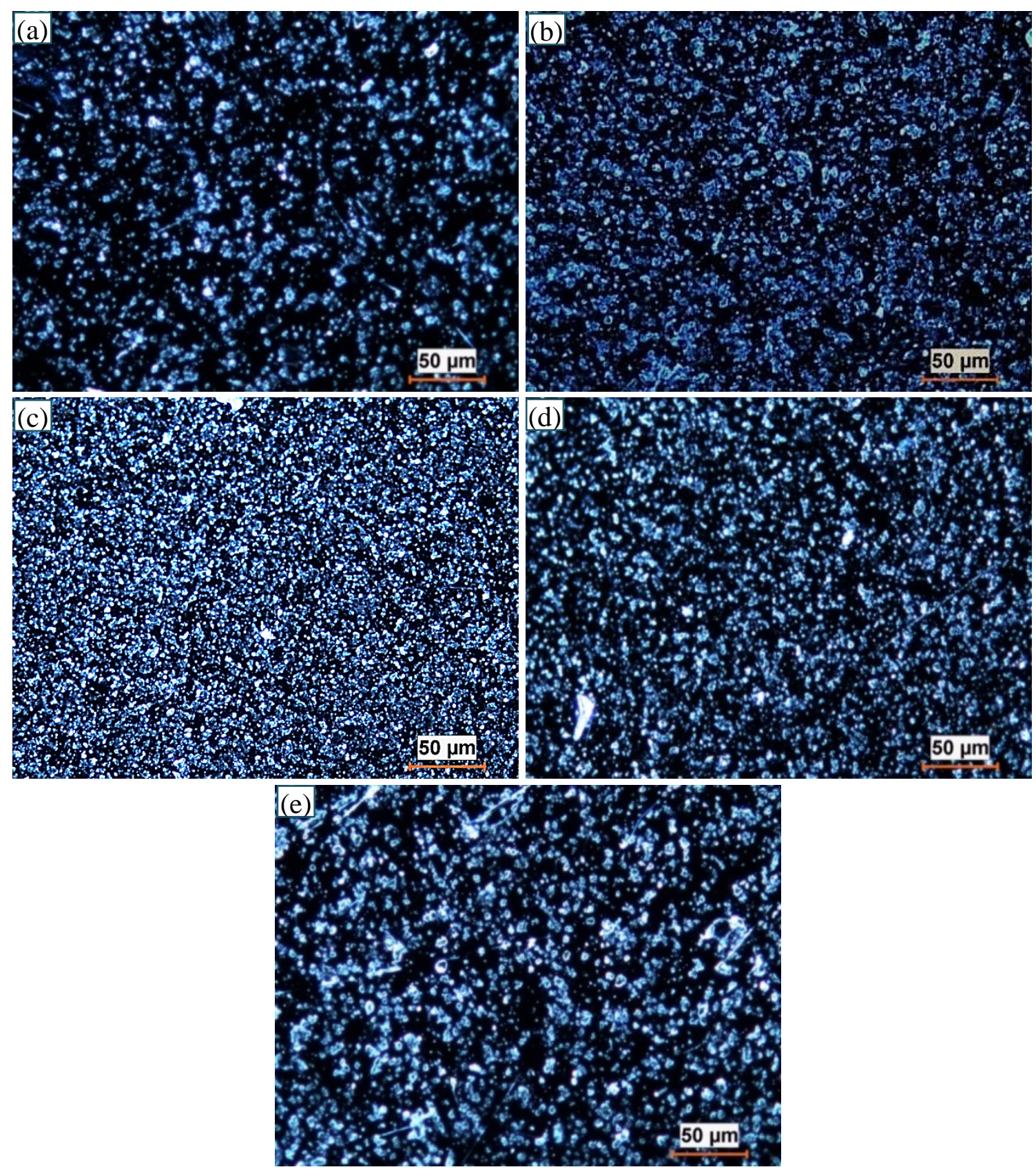

Figure 8: Optical microscopy images of (a) Pitch-1, (b) Pitch-2, (c) Pitch-3, (d) Pitch-4, and (e)

\section{Pitch-5}

The area percentages of the solid particles in pitch presented in Figure 8 (a-e) were calculated using Clemex image analysis software. The area percentages of solid particles in these five pitches ranged from $11.7 \%$ to $41.8 \%$ (Table 4). A good linear relation was observed between the QI content and the area percentage of solid particles in pitch as shown in Figure 9 (a). 
It was reported that a typical $\mathrm{C} / \mathrm{H}$ ratio for coal tar pitch is 1.8 ; primary QI material has a $\mathrm{C} / \mathrm{H}$ ratio of more than 3.5, while secondary QI has a $\mathrm{C} / \mathrm{H}$ ratio of less than 3 [1]. Typical pitch density range is from $1.3 \mathrm{~g} / \mathrm{cm}^{3}$ to $1.32 \mathrm{~g} / \mathrm{cm}^{3}$ [1]. A larger value of the $\mathrm{C} / \mathrm{H}$ ratio results in a higher density. It shows that the density of primary QI is greater than the other components in pitch. Turner et al. [14] reported that QI particles have a relatively large influence on pitch density because it has the density ranging from $2.0 \mathrm{~g} / \mathrm{cm}^{3}$ to $2.2 \mathrm{~g} / \mathrm{cm}^{3}$.

If the area corresponding to solid particles in pitch is $A_{s p}$ and the remaining pitch is $A_{r p}$, then the percentage of solid particles in pitch by area can be expressed as follows:

$$
a=\frac{A_{s p}}{A_{s p}+A_{r p}} \times 100
$$

The image analysis yields the area percentage of solid particles in pitch. However, it is more convenient to express the content in terms of weight percentage because it can be used to compare with the QI particle content of pitch given in weight percentage.

If $\rho_{\mathrm{p}}$ is pitch density and $\rho_{\mathrm{sp}}$ is solid particles density, then the weight percentage of solid particles $\left(\mathrm{W}_{\mathrm{s}}\right)$ in pitches can be expressed as follows:

$$
W s=\frac{A_{s p} \rho_{s p}}{\left(A_{s p}+A_{r p}\right) \rho_{p}} \times 100=\frac{\rho_{s p}}{\rho_{p}} \times a
$$

The percentage of solid particles found does not match with the QI \% given in Table 2. All the particles found in different pitch samples may not be QI particles. Their densities may also vary, and many particles may have a hollow center. Usually the QI particles have higher density compared to the other particles. As it is not possible to identify the QI particles specifically, it has been assumed that all the particles have densities similar to that of QI particles. This will result in a higher weight percentage of solids compared to that of the QI particles in pitch. The calculation of weight percentage has some approximations, but it gives a representative weight percent of the solid particles in pitch sample.

If all of the solid particles are QI particles, and assuming that the pitch and QI particle densities in this study are $1.31 \mathrm{~g} / \mathrm{cm}^{3}$ and $2.1 \mathrm{~g} / \mathrm{cm}^{3}$, respectively, the calculated values of solid particle area and the corresponding solid particle percentage in different pitches are presented in Table 4. 
Table 4: Solid particle area and the corresponding solid particle content in different pitches

\begin{tabular}{|l|c|c|c|c|c|}
\hline Pitch types & Pitch-1 & Pitch-2 & Pitch-3 & Pitch-4 & Pitch-5 \\
\hline Area percentage of solid particles in pitch (a) & 11.7 & 21.9 & 41.8 & 18.5 & 14.0 \\
\hline Weight percentage of solid particles $\left(\mathrm{W}_{\mathrm{s}}\right)$ & 28.0 & 42.5 & 65.4 & 38.0 & 31.5 \\
\hline
\end{tabular}

The relationship between the QI content and the solid particle percentages depending on the area percentage of solid particles in the optical microscope image of pitch is shown in Figure 9 (b). The weight percentage of solid particles in these five pitches ranges from $28.0 \%$ to $65.4 \%$ (Table 4). However, the real weight percentage of QI content in these five pitches ranges from $3.4 \%$ to $10.8 \%$ (Table 2), which is significantly lower than the values calculated from the image analysis. As explained earlier, the assumption that all the particles have density of that of QI particles $\left(2.1 \mathrm{~g} / \mathrm{cm}^{3}\right)$ resulted in a high weight percentage of solid particles. This indicates that not all of the solid particles that appeared as white dots in the optical microscopy images of pitch are QI particles. It may contain certain particles shown as solids in the optical microscopy images, but soluble in quinoline. However, a linear correlation was observed between the QI content and solid particle content, which is discussed below.
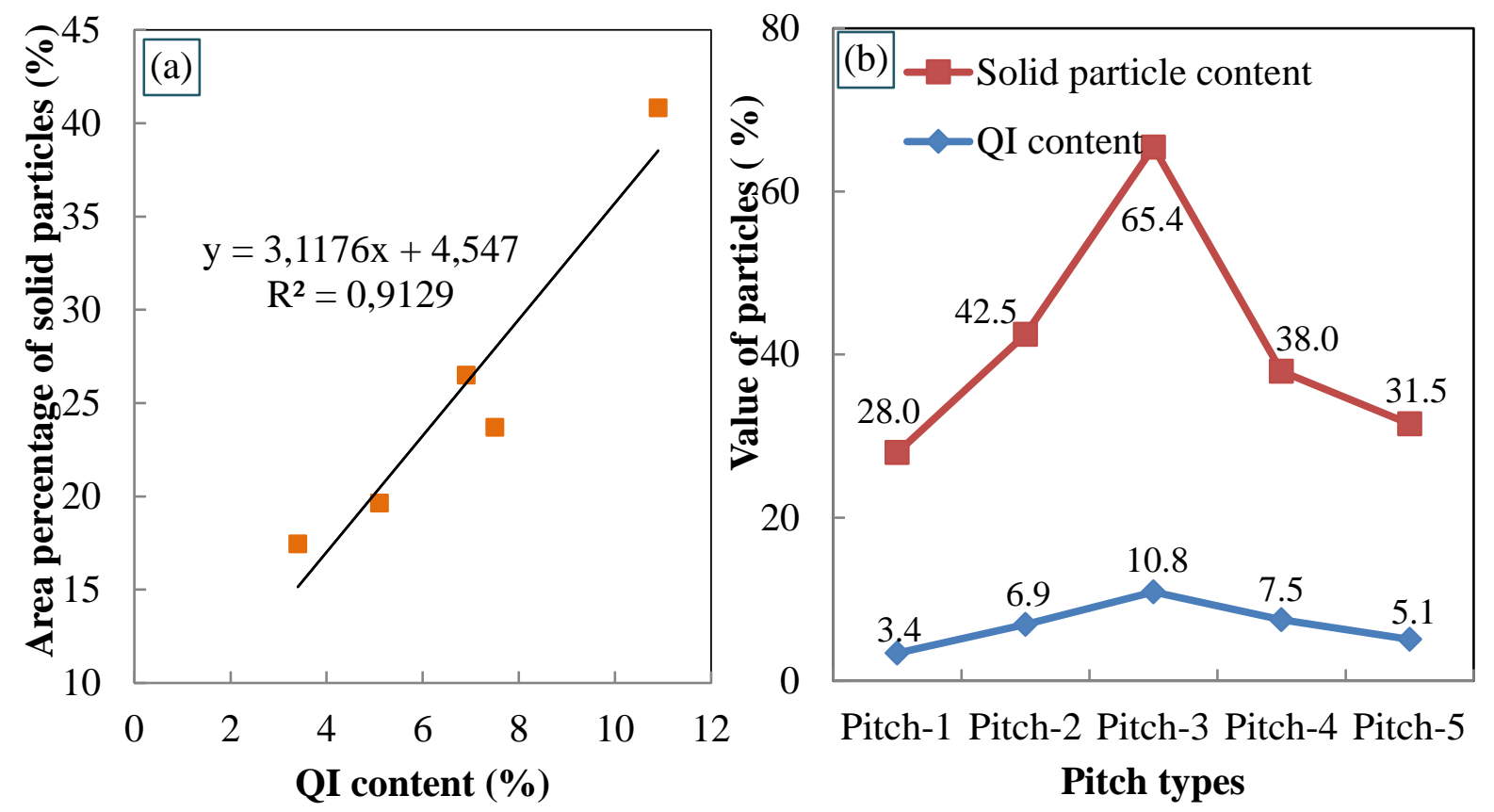
Figure 9: (a) Correlation between QI content and the area percentage of solid particles in the optical microscopy image of pitch and (b) Relationship between QI content and weight percentage of solid particles depending on the area percentage of solid particles in the optical microscopy image of pitch.

The particles sizes (maximum length) were determined using Clemex image analysis software. Figure 10 (a) shows the comparison of the number of solid particles in five different pitches using the image analysis technique. This technique may reveal the relationship between the number of solid particles and the QI content of the different pitches. The solid particles in Pitch-3 show the highest number, while Pitch-1 has the lowest number. The number of solid particles in the pitches gives a linear relation with the QI content of the corresponding pitches (Figure 10 (b)). The number of particles increased with increasing QI content.

Figure 10 (c) shows the particle size distribution in different pitches. The size of most of the particles is approximately $1 \mu \mathrm{m}$. The size of primary QI is approximately $1 \mu \mathrm{m}$ [12], and the size of the secondary QI particles is greater than that of normal primary QI [12]. It is possible that most of the particles represent primary QI. It is difficult to identify the types of all of the particles; the particle size of 2 - $4 \mu \mathrm{m}$ might be mesogens, and the particle size $>4 \mu \mathrm{m}$ might be mesophase or carbon black. The different solid particle sizes $(1-10 \mu \mathrm{m})$ are grouped into two regions: small particle-size region (1-3 $\mu \mathrm{m})$ and large particle size region $(4-10 \mu \mathrm{m})$. As can be seen in Figure 10 (d), in the small particle-size region, the particle count (\%) of Pitch-5 is the lowest; however, in the large particle-size region, the particle count (\%) of Pitch-5 is the highest. This might have decreased the wetting ability of Pitch-5 even this pitch had relatively high heteroatom content. This will be discussed further in the following sections. 


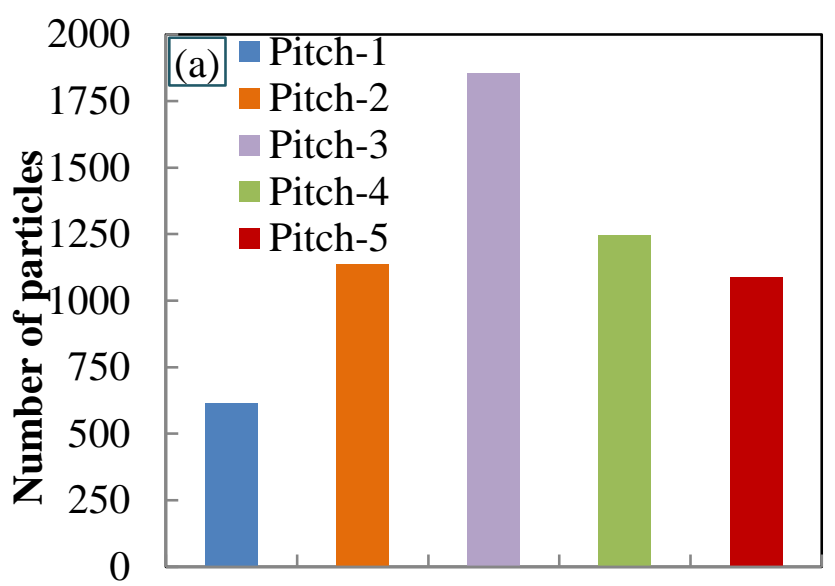

Pitch-1 Pitch-2 Pitch-3 Pitch-4 Pitch-5

Pitch types

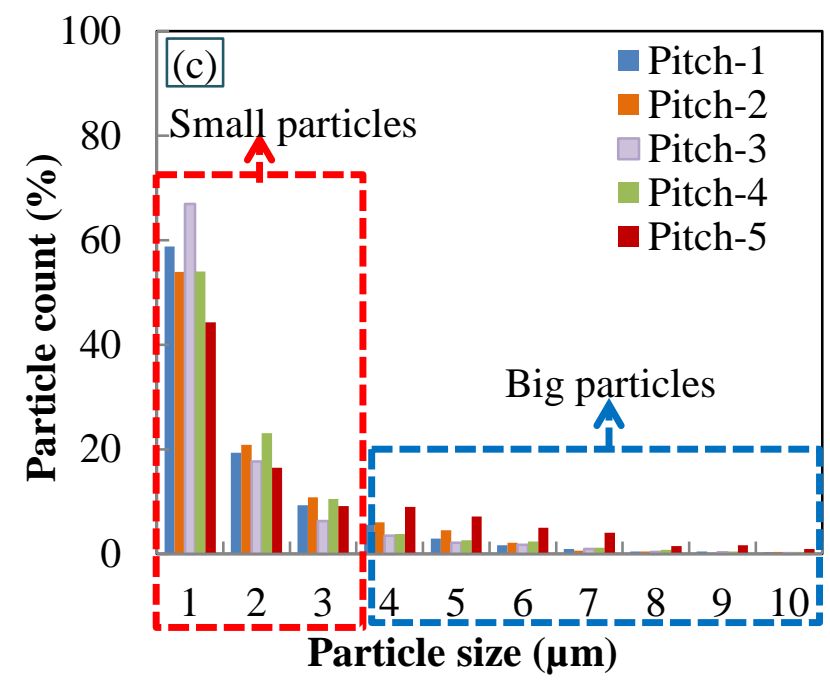

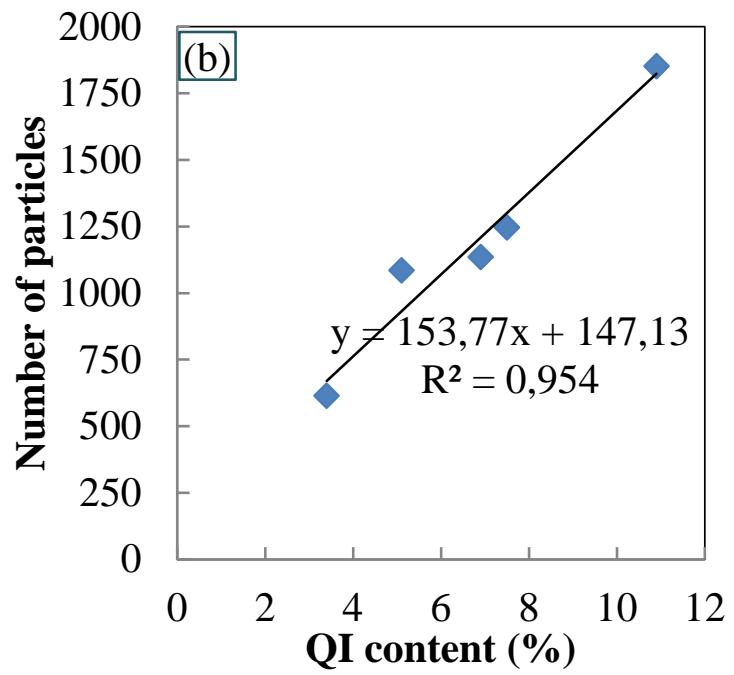

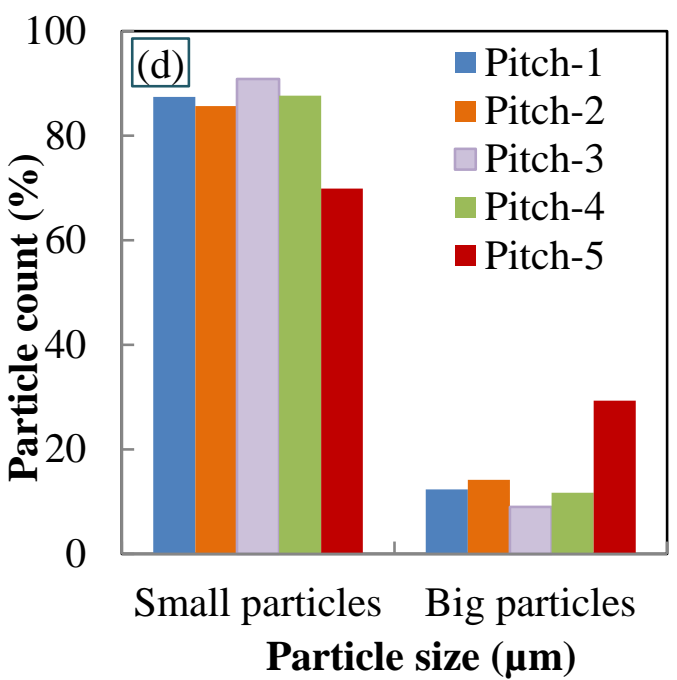

Figure 10: (a) Number of particles in five different pitches, (b) Relationship between the number of particles and the QI content, (c) Particle size distribution in different pitches, (d) Comparison of particle size distribution.

\subsection{SEM analysis}

The analysis of the pitch-coke interface was done with the scanning electron microscopy (SEM) at high magnification. For the analysis, the sessile drop samples obtained from the contact angle experiments were used. It should be noted in this case that the pitch and coke samples used had been heated to $170{ }^{\circ} \mathrm{C}$ whereas the FT-IR and XPS analyses of pitches and coke as well as the optical microscopy analysis of pitches were carried out on samples at room temperature without prior heating. Thus, the results obtained with the optical microscopy may not be agree 
with the results obtained using SEM because of the heating of the pitch which may have altered the coke-pitch interactions and the pitch structure.

Figure 11 shows the interfaces of five pitches with the coke. It is possible to differentiate pitch and coke particles in these images. All of the pitch surfaces contain solid particles. It was reported that the size of primary QI is approximately $1 \mu \mathrm{m}[1,12]$, and the size of the secondary QI particles is greater than $1 \mu \mathrm{m}$ [12]. Both of them are also spherical. It can be seen that there are particles with shapes other that spherical in Figure 11 (a-e). Hence, the SEM images also indicate that all of the pitches used in this study contain particles with characteristics similar to those of primary QI. However, it is difficult to arrive at a conclusion that all are QI particles.

It was observed that the particles of Pitch-5 showed agglomeration (size of agglomerated layer much greater than $18 \mu \mathrm{m}$ ) and patchy distribution compared to those in other pitches (Figure 11 (e)). As mentioned previously, the optical microscopy results showed that Pitch-5 had large agglomerated particles. The optical microscopy and SEM results showed that the particle size distribution in all of the pitches might vary before and after heating or in the presence of the coke particles (see Figure 8 (a-e) and Figure 11 (a-e)). It is possible that heating might have changed the chemical nature of particles in pitch. 

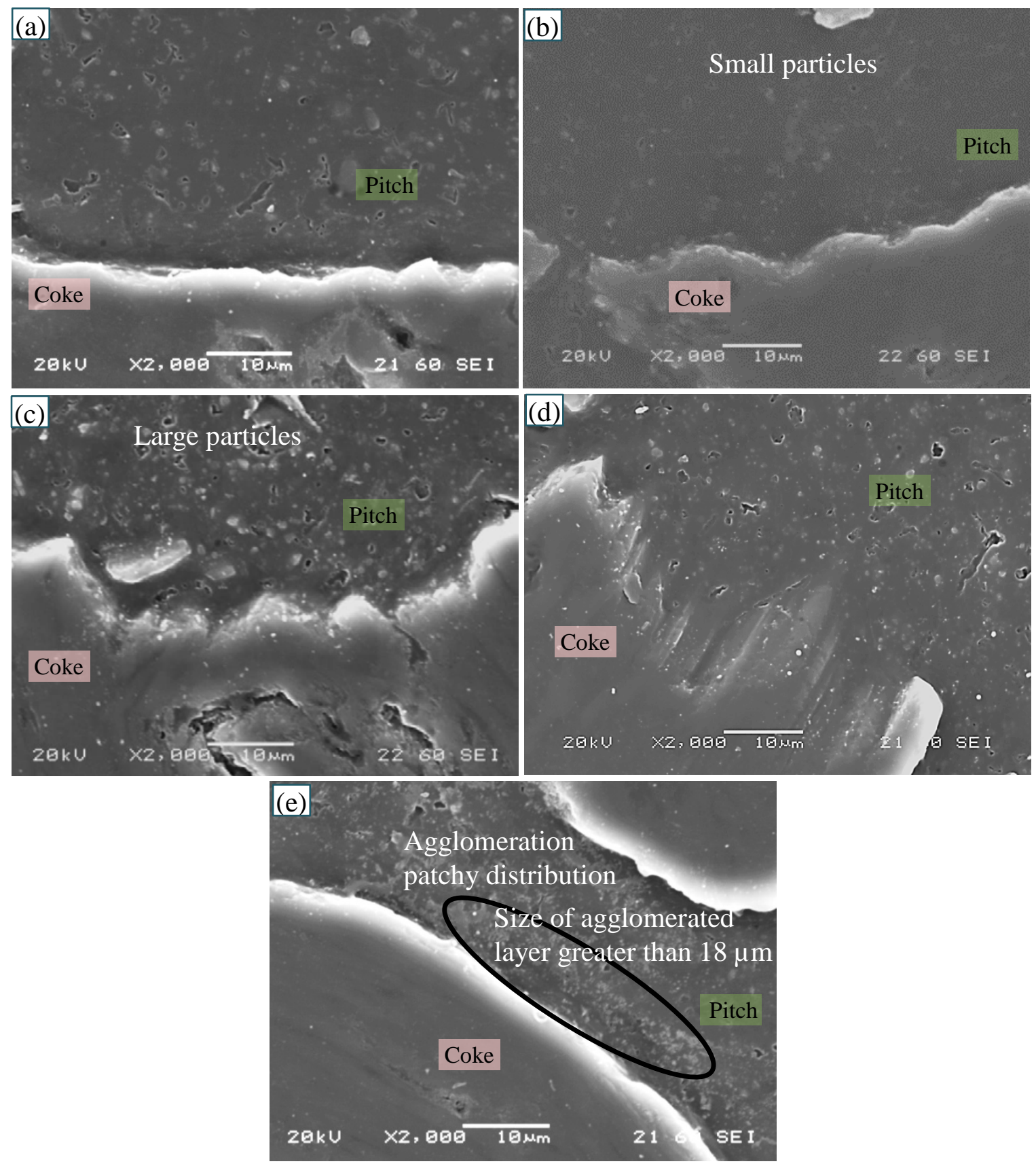

Figure 2: SEM images of (a) Pitch-1/Coke, (b) Pitch-2/Coke, (c) Pitch-3/Coke, (d) Pitch-4/Coke, and (e) Pitch-5/Coke Interface

3.7 Effect of different parameters on the wettability of coke by different pitches

Wettability of pitch by coke depends on a number of parameters. In this study the effects of different parameters have been analyzed with a view to identify the key parameters controlling 
the wettability of coke by pitch. A smaller contact angle indicates better wettability of coke by pitch. Different parameters were plotted against the contact angle at $60 \mathrm{~s}$. A linear trend line was found for each of the cases, and the coefficient of regression has been noted. Figure 12 presents the coefficient of regression of different parameters. The white columns represent the parameters enhancing the wettability while the black ones showed the parameters decreasing the wettability. The value of the coefficient of regression close to unity indicates significant dependency contact angle on that particular parameter.

FT-IR results show that coke and pitch contained different functional groups that can influence coke-pitch interactions. It cannot justify the differences in the wettability. XPS study shows that increase in $\mathrm{C}$ and $\mathrm{C}-\mathrm{C}$ contents increased the contact angle. Increase in carbon percentage decreased heteroatom content. Reduction of wettability by $\mathrm{C}-\mathrm{C}$ can be attributed to the steric hindrances offered by the alkyl chains. Increase in the heteroatoms and heteroatomcontaining functional groups helped decrease the contact angle. Heteroatoms enhance condensation reactions and hydrogen bonding, thereby improving wettability of coke by pitch. $\mathrm{C}=\mathrm{C}$ can be attributed to aromatic content which can improve wetting though electrostatic interaction. Thus, increase in $\mathrm{C}=\mathrm{C}$ reduced the contact angle at $60 \mathrm{~s}$. Among the different chemical interactions $\mathrm{C}$, $\mathrm{O}$, total heteroatom content and heteroatom containing functional groups showed high values of the coefficient of regression (Figure 12). Hence, these four parameters have significant effect on the wettability of coke by different pitches. As increase in C content is directly related to decrease in heteroatom content, it can be concluded that heteroatoms, especially oxygen, helps improve wettability of coke by pitch.

Figure 12 shows that increase in viscosity decreased wettability of coke by pitch. Increase in viscosity reduced the flow of pitch into the coke bed resulting in higher contact angle at $60 \mathrm{~s}$. It has the highest regression coefficient which shows that viscosity of pitch is a major parameter that controls the wettability of coke by pitch. As it was previously mentioned, the wettability decreased in the following order Pitch-1 being the best wetting: Pitch-1 > Pitch-2 > Pitch-3 > Pitch-5 > Pitch-4. From Table 2, it can be seen that the viscosity of the pitches increased from Pitch-1 to Pitch-4 and Pitch-5 had viscosity lower than that of Pitch-4 but higher than those of other pitches.

Figure 12 also shows the effect of the particles in pitch. Total solid content in pitch analyzed by optical microscopy showed practically no influence on the wetting behavior. QI content had 
some influence whereas large particles had more influence on wettability. The number of particles increased with increasing QI content; however, no direct relationship was found between the QI content of the pitch and the wettability of coke by these pitches. The number of large particles (size $4-10 \mu \mathrm{m}$ ) of Pitch-5 is the highest among these pitches. This may have contributed to the wetting test results obtained above (Pitch-5 being the lowest wetting even though the atomic percentages of $\mathrm{O}, \mathrm{N}$, and $\mathrm{S}$ are reasonably high). Figure 2 shows that the pores in the coke particles are smaller than the solid particle size. Thus, the solid particles can block coke pores. Figure 3 shows that particles larger than $16 \mu \mathrm{m}$ cannot enter the pores between the coke particles. Thus, large particles or agglomerated particles can block the pores of the coke bed resulting in poor wetting. It is enough to block the pores even if only two to three large particles form agglomerates. Therefore, it is a highly possible that large particles of Pitch-5, after $60 \mathrm{~s}$, may have blocked the pores of coke as well as that of coke bed preventing the penetration of pitch. Then, it might be be said that the presence of large particles and agglomeration of particles in Pitch-5 might have caused poor wetting in spite of having high heteroatom content, and medium viscosity.

The results showed that high heteroatom content, low viscosity and small particle size help improve wettability of coke by pitch. Agglomeration of particles in pitch can override the effect heteroatom content and viscosity, and deteriorate the wettability of coke by pitch. 


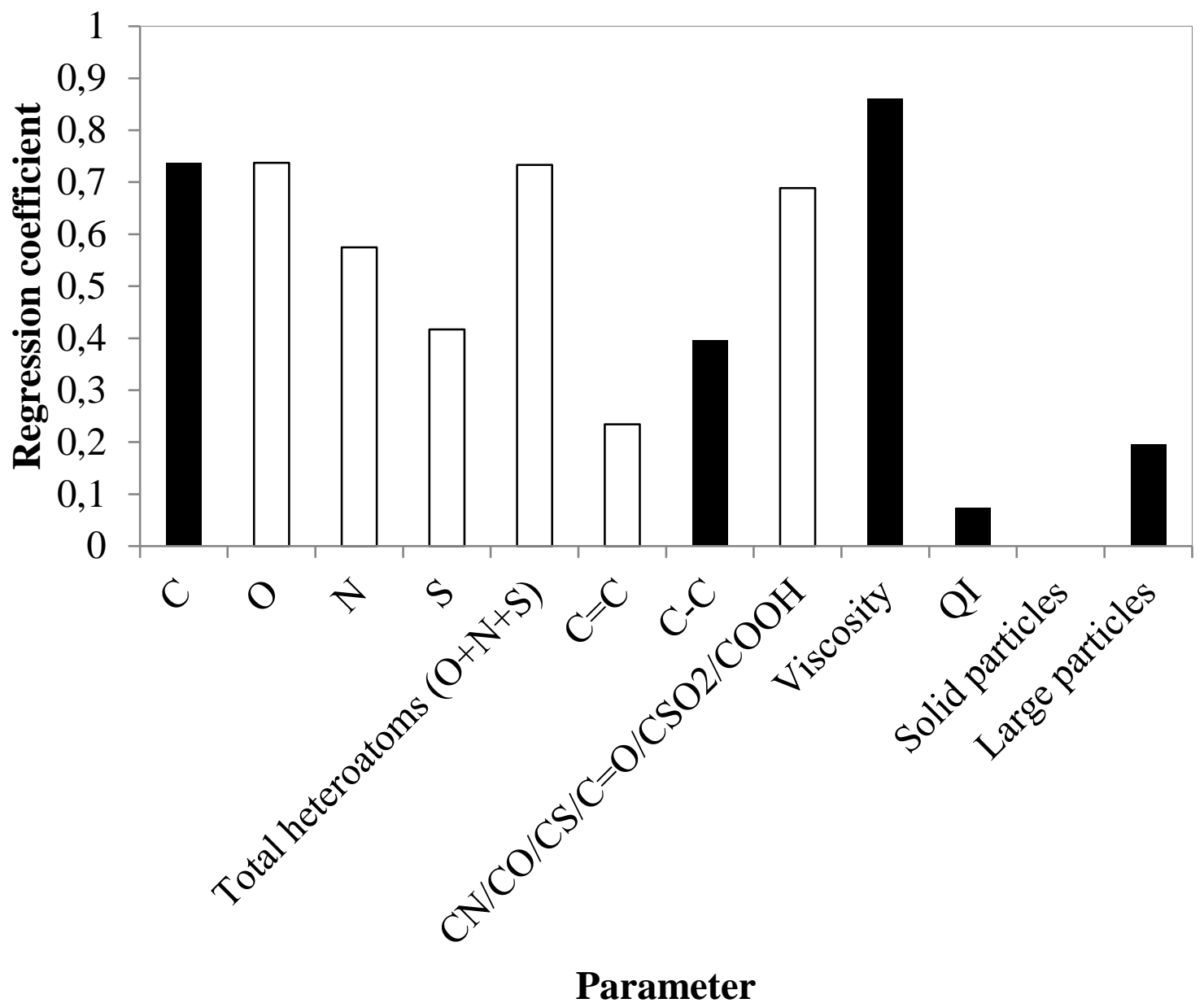

Figure 12. Effect of different parameters on the wettability of coke by pitch (black: increases contact angle with increase in the parameter; white: decreases contact angle with increase in the parameter) 


\section{Conclusions}

The dynamic contact angle results showed that the wettability of five pitches with different properties on the same coke is significantly different. Their QI content as well as the solid particle quantity and particle size distribution have a significant effect on wetting. The wettability results show that both the chemical and physical properties of pitches contribute to the wettability of coke by pitch.

The FT-IR results indicated that the petroleum coke and coal tar pitch contained complimentary functional groups, and the functional groups on the coke surfaces can interact with the functional groups present on pitch surfaces, as confirmed by the XPS results. The XPS results showed that as the QI content increased (except for Pitch-4), the percentages of O, N increased, and the possibility for chemical interactions between coke and pitch functional groups increased, thus increasing the wettability.

The optical microscopy analysis showed that the amounts and size distributions of solid particles in these pitches with different QI contents are different. It is observed that the QI particle size of Pitch-5 is the largest among the five different pitches. This may have contributed to the wetting test results obtained for the five pitches (such as the lowest wetting for Pitch-5, even though the atomic percentages of $\mathrm{O}$ and $\mathrm{N}$ are reasonably high). The SEM analysis indicated that the QI particles of Pitch-5 were agglomerated and had a patchy distribution compared to the other pitches. Therefore, the interaction between Pitch-5 and the coke is reduced because the pores of the coke are blocked by QI particles. The level of QI and the QI particle size and distribution in pitches play a significant role in the wettability of coke by pitch, possibly explaining why the wettability of Pitch-5 is the lowest. The results showed that the size distribution of solid pitch particles affects the wetting. Large particles may accumulate and form a barrier, which prevents the pitch penetration into the coke.

The results showed that the wettability of coke by pitch can improve due to high heteroatom content, low viscosity and small particle size. However, the agglomeration of particles in pitch can override the effect heteroatom content and viscosity, and reduce the wettability of coke by pitch. 


\section{Acknowledgements}

The technical and financial support of Aluminerie Alouette Inc. (AAI) as well as the financial support of the Natural Sciences and Engineering Research Council of Canada (NSERC), Développement économique Sept-Îles, the University of Québec at Chicoutimi (UQAC), and the Foundation of the University of Québec at Chicoutimi (FUQAC) are greatly appreciated.

\section{References}

1. K.L. Hulse, Anode manufacture : Raw materials, formulation and processing parameters (Sierre [Suisse]: R \& D Carbon Ltd., 2000), xxxv, 416 p.

2. P. Couderc, P. Hyvernat, and J.L. Lemarchand, "Correlations between ability of pitch to penetrate coke and the physical characteristics of prebaked anodes for the aluminium industry,” Fuel. 65(2) (1986), p. 281-287.

3. D. Hays, J.W. Patrick, and A. Walker, "A scanning electron microscope study of fractured and etched metallurgical coke surfaces,” Fuel. 61(3) (1982), p. 232-236.

4. V.G. Rocha, C. Blanco, R. Santamaría, E.I. Diestre, R. Menéndez, and M. Granda, “An insight into pitch/substrate wetting behaviour. The effect of the substrate processing temperature on pitch wetting capacity,” Fuel. 86(7-8) (2007), p. 1046-1052.

5. V.G. Rocha, C. Blanco, R. Santamaría, E.I. Diestre, R. Menéndez, and M. Granda, “The effect of the substrate on pitch wetting behaviour,” Fuel Processing Technology. 91(11) (2010), p. 1373-1377.

6. A. Sarkar, D. Kocaefe, Y. Kocaefe, D. Bhattacharyay, B. Morais, and M. Pouliot. Characterization of petroleum coke and butts used in anode manufacturing in aluminum industry. in Materials Science and Technology Conference and Exhibition 2013, MS and T 2013. 2014. Montreal, QC.

7. A. Sarkar, D. Kocaefe, Y. Kocaefe, D. Sarkar, D. Bhattacharyay, B. Morais, and J. Chabot, “Coke-pitch interactions during anode preparation,” Fuel. 117(PART A) (2014), p. 598-607.

8. M.B. Dell, and R.W. Peterson, "Wettability of petroleum cokes by pitch," Industrial and Engineering Chemistry Product Research and Development. 9(2) (1970), p. 190-194.

9. X. Huang, D. Kocaefe, Y. Kocaefe, and D. Bhattacharyay, "Wettability of bio-coke by coal tar pitch for its use in carbon anodes," Colloids and Surfaces A: Physicochemical and Engineering Aspects. 490 (2016), p. 133-144.

10. S.S. Jones, and R.D. Hildebrandt, Electrode binder pyrolysis and bond-coke microstructure (John Wiley and Sons, Vol. 4. 2013).

11. A. Alscher, W. Gemmeke, F. Alsmeier, and W. Boenigk. Evaluation of electrode binder pitches for the production of prebaked anodes using a bench scale process. in AIME Annual Meeting. 1987. Warrendale, PA, USA. Denver, CO, USA: Light Metals.

12. A. Alscher, R. Wildfoerster, and J.A. Sharp, Performance of binder pitches with decreased qi-content in anode making formation - nature - properties and substitution of quinoline insolubles, in TMS (The Minerals, Metals \& Materials Society) Annual Meeting 
and Exhibition, C.M. Bickert, Editor. 1990, Light Metals: San Diego, California. USA. p. 232-236.

13. R.H. Wombles, and J.T. Baron. Laboratory anode comparison of chinese modified pitch and vacuum distilled pitch. in TMS. 2006. San Antonio, TX.

14. N. Turner, Influence of pitch qi particle type and size on anode quality. The volatiles emitted from bench-scale anodes during bake, in TMS (The Minerals, Metals \& Materials Society) Annual Meeting and Exhibition, E. Cutshall, Editor. 1992, Light Metals: San Diego, CA. p. 571-580.

15. M. Sakai, Y. Wang, T. Fukuoka, and H. Hatano, Importance of primary quinoline insoluble in binder pitch for anode, in TMS (The Minerals, Metals \& Materials Society) Annual Meeting and Exhibition, C.E. Suarez, Editor. 2012, Light Metals: Orlando, FL. p. 1223-1228.

16. T.A. Golubic, S.A. McKinney, and R.H. Wombles, High softening point coal tar pitch as anode binder pitch, in TMS (The Minerals, Metals \& Materials Society) Annual Meeting and Exhibition, J.A. Johnson, Editor. 2010, Light Metals: Seattle, WA. p. 909-911.

17. W. Boenigk, A. Niehoff, and R. Wildfoerster, Influence of qi content on binder pitch performance, in TMS (The Minerals, Metals \& Materials Society) Annual Meeting and Exhibition, E. Rooy, Editor. 1991, Light Metals: New Orleans, LA. p. 615-619.

18. P.J. Rhedey, Laboratory evaluation of a low quinoline insolubles coal-tar pitch as anode binder, in TMS (The Minerals, Metals \& Materials Society) Annual Meeting and Exhibition, C.M.Bickert, Editor. 1990, Light Metals: Warrendale, PA,Anaheim, CA. p. 605-608.

19. N.R. Turner, Improvements in anode binder pitches by advances in raw materials handling, manufacturing and transportation, in TMS (The Minerals, Metals \& Materials Society) Annual Meeting and Exhibition, C.M.Bickert, Editor. 1990, Light Metals: Warrendale, PA,Anaheim, CA. p. 629-638.

20. Anon, Year-book of the coke oven managers' association 1984 (Coke Oven Managers' Association (Year Book) Ltd, Mexborough, 1984), 247p.

21. D. Belitskus, and W. Hill, Properties of bench scale anodes produced using binder pitches varying in primary and secondary qi contents, in TMS (The Minerals, Metals \& Materials Society) Annual Meeting and Exhibition, C.M. Bickert, Editor. 1990, Light Metals: Anaheim, CA, USA. p. 577-581.

22. K.D. Lu.Y, Kocaefe.Y, Bhattacharyay.D, Huang.X, Morais.B, Study of the wetting of coke by different pitches, in TMS (The Minerals, Metals \& Materials Society) Annual Meeting and Exhibition, E. Williams, Editor. 2016, Light Metals: Nashville, TN. p. 871876.

23. M.D. Guillén, M.J. Iglesias, A. Domínguez, and C.G. Blanco, "Semiquantitative ftir analysis of a coal tar pitch and its extracts and residues in several organic solvents," Energy \& Fuels. 6(4) (1992), p. 518-525.

24. D. Hays, J.W. Patrick, and A. Walker, "Sem study of binder coke in electrode carbon," Fuel. 62(8) (1983), p. 946-952.

25. R. H.Wombles, and B. Sadler. The effect of binder pitch quinoline insolubles content on aluminum anode physical properties. in Australasian Aluminium Smelting Technology Conference. 2004. Queensland, AU: Coke oven managers' year book. 
